\title{
Eosinophil cationic protein in inflammatory synovial effusions as evidence of eosinophil involvement
}

\author{
R. HÄLLGREN, A. BJELLE, AND P. VENGE \\ From the Departments of Internal Medicine, and Clinical Chemistry, University Hospital, Uppsala, Sweden
}

SUMMARY Eosinophils are seldom noted in inflammatory synovial fluids but are reported to infiltrate the synovial tissue in inflammatory arthritides. To elucidate a possible role for eosinophils in inflammatory joint reactions the concentrations of eosinophil cationic protein (ECP) - a specific granule protein from eosinophils-were measured by radioimmunoassay in 90 synovial fluids from patients with various inflammatory arthritides (rheumatoid arthritis, reactive and crystal arthritides, Reiter's disease and psoriatic arthropathy). In the same specimens lactoferrin was measured as an indicator of neutrophil-involved inflammation. In comparison with the normal circulating levels of ECP and lactoferrin the measured synovial fluid concentrations of both proteins were considerably raised in all patient groups with inflammatory joint diseases in contrast to patients with non-inflammatory arthritides. There was a striking positive correlation between the ECP and lactoferrin synovial fluid concentrations. These data indicate that eosinophil activation is prominent in inflammatory joint reactions and is linked to the activation of neutrophils. The regulation of degranulation or secretion by eosinophils is unknown. Our in-vitro studies showed that peripheral blood isolated neutrophils as well as eosinophils degranulated when exposed to IgG complexes. However, eosinophil degranulation was modest compared with neutrophil degranulation. These data suggest that neutrophil phagocytosis of, for example, immune complexes may be one major mechanism in neutrophil degranulation but that other factors determine the appearance of eosinophil products in inflammatory synovial effusions. The possible modulatory or harmful role of eosinophils in inflammatory joint disease can at present only be speculated on.

Key words: neutrophils, lactoferrin, $\beta$-thromboglobin, degranulation.

The protein content of the granules of the eosinophil granulocyte is dominated by the presence of highly cationic proteins. One of these proteins, the eosinophil cationic protein (ECP), has been characterised as a zinc-containing single-chained protein with an apparent molecular weight of $21000 .^{1} \mathrm{By}$ the use of a sensitive radioimmunoassay for $\mathrm{ECP}^{2}$ it has been possible to study the turnover and activity of eosinophils in various biological fluids. The synovial fluid of patients with inflammatory arthritides contain mainly neutrophils, while eosinophils are rare in inflammatory synovial effusions. ${ }^{3}$ Lyso-

Accepted for publication 4 April 1984.

Correspondence to Associate Professor R. Hällgren, Section of Rheumatology, Department of Internal Medicine, University Hospital, S-751 85 Uppsala, Sweden. somal enzymes from neutrophils have long since been identified in high concentrations in the synovial fluid of inflammatory joint disease, and in consequence neutrophils have been considered at least partly responsible for the cartilage destruction in inflamed joints. ${ }^{4}$ Since eosinophils are absent from inflamed synovial fluids, a possible role of eosinophils in arthritic conditions has not been considered before.

In the present study we have measured in inflammatory synovial fluids the concentrations of ECP together with lactoferrin, a specific constituent of the secondary granules of neutrophils. ${ }^{5}$ The main purpose of the study was to elucidate the possible eosinophil involvement in inflammatory joint reactions and whether or not local eosinophil activation was paralleled by local neutrophil activation. 


\section{Patients and methods}

PATIENTS AND SYNOVIAL FLUID COLLECTION Synovial fluid samples were collected at the time of a clinically indicated arthrocentesis. The synovial fluids, anticoagulated with heparin, were centrifuged and the cell-free supernatants stored at $-70^{\circ} \mathrm{C}$ before analysis in sequence. Arthrocentesis was performed in 90 patients with various inflammatory joint diseases, and some of their clinical features are presented in Table 1 . The majority of the patients were taking non-steroidal anti-inflammatory agents, and a smaller number received prednisolone in low doses. Arthrocentesis was also performed in seven patients with non-inflammatory arthritides (osteoarthritis (3) and trauma (4)).

ASSAYS OF ECP, LACTOFERRIN, AND

$\beta$-THROMBOGLOBULIN IN SYNOVIAL FLUID

Radioimmunoassay of ECP and lactoferrin were performed as previously described. ${ }^{26}$ The $95 \%$ normal serum ranges of these proteins are $5-55 \mu \mathrm{g} / 1$ and $190-645 \mu \mathrm{g} / \mathrm{l}$, respectively. $\beta$-Thromboglobulin $(\beta-T G)$ was assayed by the use of a commercial kit (Amersham Int. PLC, Amersham, UK). The normal mean plasma $\beta$-TG value at our laboratory is 24 $\mu \mathrm{g} / \mathrm{l}, 2 \mathrm{SD}$ ranges $\leqslant 10-50$. All synovial fluid samples were analysed in duplicate. The coefficients of variation of the assays were below $9 \%$. Hyaluronidase digestion of samples did not significantly alter assay sensitivity or assay non-specific binding. Parallel standard curves were obtained for both proteins by means of the respective protein standards mixed with either buffer or a constant volume of synovial fluid.

GRANULOCYTES DEGRANULATION IN VITRO Granulocytes were isolated from heparinised normal venous blood as previously described ${ }^{7}$ and diluted to a cell concentration of $8 \times 10^{9} \mathrm{PMNs} / 1$ in Ringerdex buffer (Pharmacia AB, Uppsala, Sweden) with added glucose $(7 \mathrm{mmol} / \mathrm{l})$ and human albumin ( $5 \mathrm{~g} / \mathrm{l}$, Kabi, Stockholm, Sweden). $2 \mathrm{ml}$ of the granulocyte suspension was added to a siliconised cuvette containing a siliconised stirring bar revolving at $1000 \mathrm{rpm}$. After a 2 min delay to allow warming of the cells to $37^{\circ} \mathrm{C}, 200 \mu \mathrm{l}$ of the sample to be tested was added. At defined time intervals $200 \mu \mathrm{l}$ from the granulocyte mixture was aspirated and added to a plastic tube containing $500 \mu \mathrm{l} 0.1 \%$ EDTA (w/v) in saline, $\mathrm{pH} 7 \cdot 5$, precooled to $0^{\circ} \mathrm{C}$ in an ice-bath. The tubes were centrifuged at $3000 \mathrm{~g}$ at $4^{\circ} \mathrm{C}$ for $10 \mathrm{~min}$ and the supernatants kept frozen at $-80^{\circ} \mathrm{C}$ until analysed in sequence for ECP and lactoferrin by radioimmunoassays. Aggregated IgG (agg IgG) was used as the test substance for degranulation activity. Agg IgG was produced by heating $2 \%(\mathrm{w} / \mathrm{v}) \operatorname{IgG}(\mathrm{Kabi})$ in saline at $63^{\circ} \mathrm{C}$ for 30 min. The influence of serum on the degranulation reaction was studied by preincubation of agg IgG with $10 \%(w / v)$ fresh autologous serum (NHS). The amounts of granule proteins released were corrected for the background values obtained in control experiments. Lactate dehydrogenase (LD) was determined according to Wroblewski and LaDue ${ }^{8}$ and was used as an expression of viability.

Table 1 The synovial fluid concentrations (geometric means) of ECP and lactoferrin in various forms of arthritidis

\begin{tabular}{lcclllll}
\hline & $n$ & $M / F$ & $\begin{array}{l}\text { Mean age } \\
\text { range) } \\
\text { years }\end{array}$ & $\begin{array}{l}\text { Duration of disease } \\
\text { (ranges) } \\
\text { years }\end{array}$ & $\begin{array}{l}E C P \\
(2 S D \text { ranges })\end{array}$ & $p^{*}$ & $\begin{array}{l}\text { Lactoferrin } \\
(2 \text { SD } / 1\end{array}$ \\
$\mu \mathrm{g} / \mathrm{l}$
\end{tabular}

${ }^{*} \mathrm{p}$ values versus patients with rheumatoid arthritis $\mathrm{NS}=$ not significant at $5 \%$ level 
The intracellular content of ECP and lactoferrin was determined by extraction of the isolated granulocytes with $0.3 \% \quad(w / v)$ cethyltrimethylammoniumbromide (CTAB) in $0.01 \mathrm{M}$ phosphate buffer, $\mathrm{pH} 7 \cdot 2$. The extraction was carried out at $22^{\circ} \mathrm{C}$ with frequent suctions by means of a Pasteur pipette. After centrifugation at $1200 \mathrm{~g}$ for 20 min the supernatant was assayed for ECP and lactoferrin.

Student's $t$ test was applied in the statistical analysis of data.

\section{Results}

\section{PATIENT STUDIES}

Fig. 1 illustrates the individual synovial fluid concentrations of ECP in patients with various types of arthritis. The highest ECP levels were noted in patients with rheumatoid arthritis. However, because of the variation in the concentrations, the synovial fluid levels of ECP in rheumatoid arthritis were significantly elevated compared only with the levels found in patients with reactive arthritides (i.e., arthropathies following infectious diseases) or arthritis associated with sacroiliitis or ankylosing spondylitis (Table 1). Age, sex, or disease duration did not influence the ECP values. The synovial fluid concentrations of ECP were considerably raised compared with the serum ECP concentrations found in healthy individuals (Fig. 2). In a number of patients with rheumatoid arthritis $(n=14)$ we also assayed their serum concentrations of ECP. These were increased on average four times compared with those of healthy controls (Fig. 2). The ECP levels in the synovial fluid of these patients were on average eight times higher than in the circulation (Fig. 2). There was no correlation between the values in the circulation and those in the synovial fluid. In patients with non-inflammatory arthritides we found very low synovial fluid values of ECP and of approximately the same magnitude as those in the circulation of healthy individuals (Fig. 2).

The lactoferrin concentrations of the synovial fluids are presented in Table 1. Increased local neutrophil activity was evident in all diagnostic groups but most prominent in rheumatoid arthritis, Reiter's disease and crystal arthritides. In these disorders the mean synovial fluid concentrations were approximately 10 times higher than the normal circulating lactoferrin levels. In contrast only 3 out of 44 patients with rheumatoid arthritis and none of the patients with other inflammatory arthritides had $\beta$-TG concentrations in synovial fluid exceeding the upper normal range of plasma $\beta-T G$. Since $\beta-T G$ is a platelet-specific substance, which is released from activated platelets, ${ }^{9}$ these results do not support a major local platelet activation in inflamed joints in contrast to the pronounced neutrophilic and eosinophilic activation.

The ECP synovial fluid concentrations were positively related to the lactoferrin concentrations. This relationship was valid when calculated for all patients $(p<0.001)$, patients with RA $(p<0.001)$ or patients with reactive arthritides $(p<0.001)$ (Figs. 3 and 4). Patients with crystal arthritides showed a similar relationship between ECP and lactoferrin as

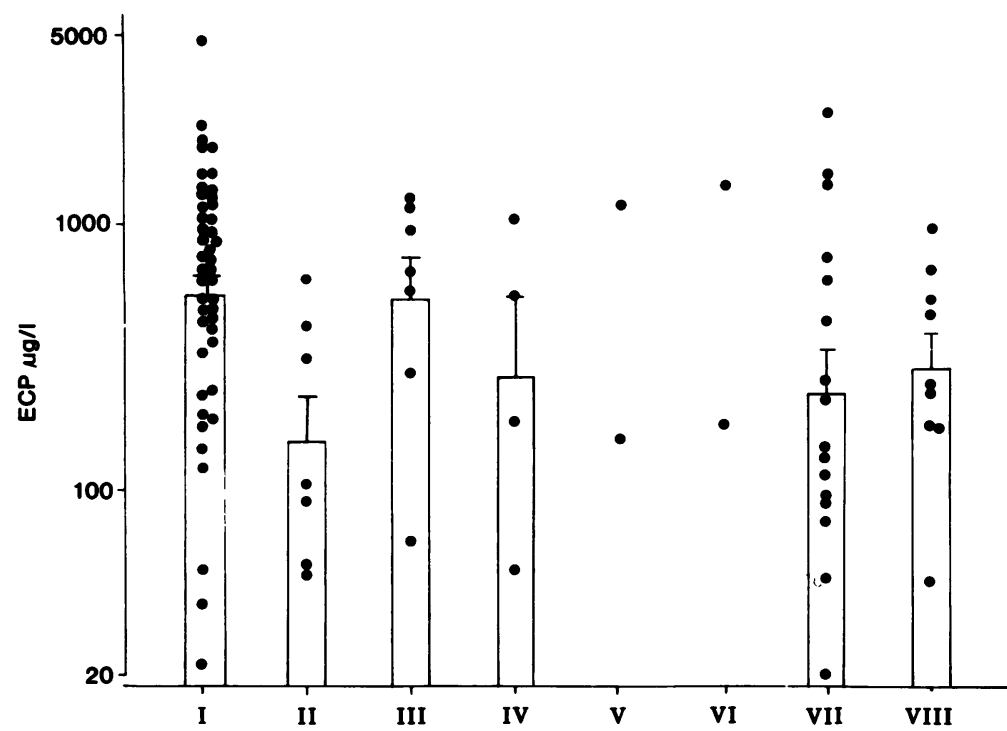

Fig. 1 Synovial fluid concentrations of ECP in patients with rheumatoid arthritis (I), Reiter's syndrome (II), sacroiliitis pelvospondylitis (III) psoriatic arthritis (IV), pyrophosphate arthritis (V), gout (VI), reactive arthritis (VII), and unclassified arthritis (VIII). The geometric means with SEM are also shown. 


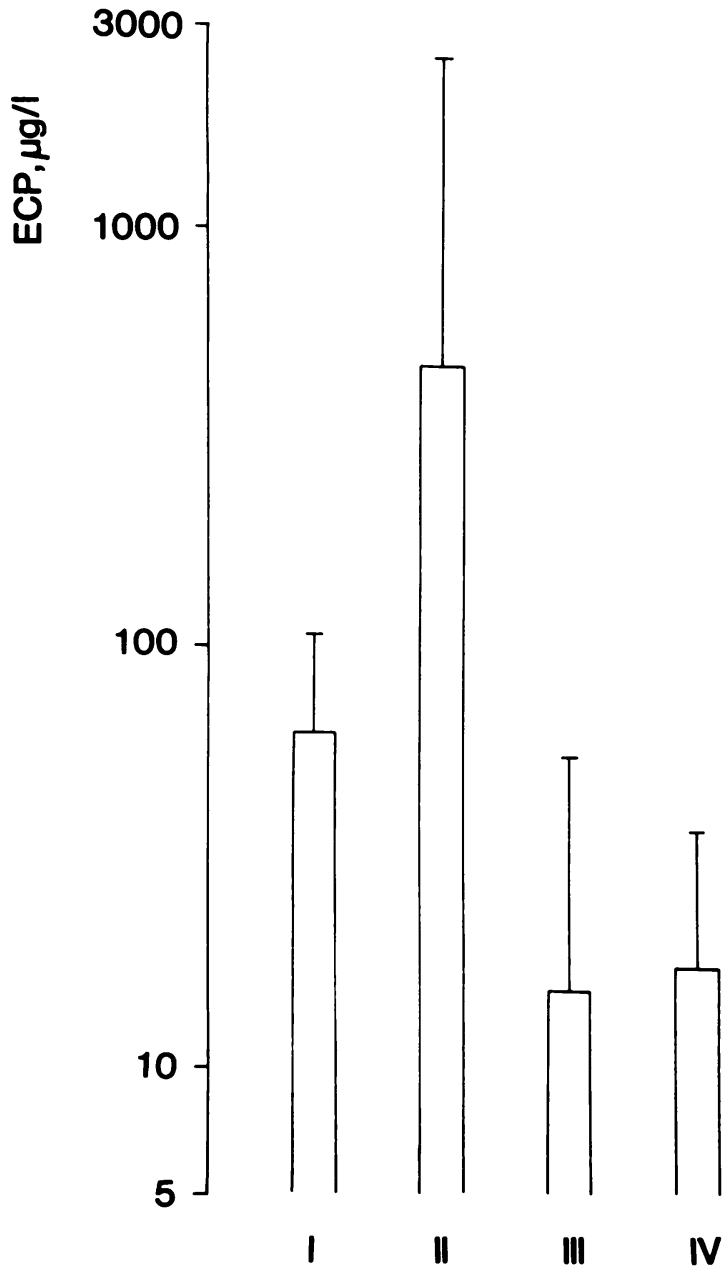

Fig. 2 The geometric mean values $\pm 2 S D$ of ECP in the circulation (I) and in the synovial fluid (II) in a group of patients $(n=14)$ with rheumatoid arthritis. The serum concentrations of ECP in a healthy reference population $(n=82)$ (III) and the synovial fluid values in patients $(n=7)$ with non-inflammatory arthritides (IV) are also shown.

noted in the other kinds of arthritis (Fig. 4). No correlation was found between the $\beta$-TG values and the ECP or lactoferrin concentrations.

\section{DEGRANULATION STUDIES}

As illustrated in Fig. 5, agg IgG induced an immediate onset of extracellular release of both ECP and lactoferrin. The release of the two granule proteins was further enhanced by the preincubation of agg IgG with fresh serum (NHS). A dosedependent release reaction was evident for both

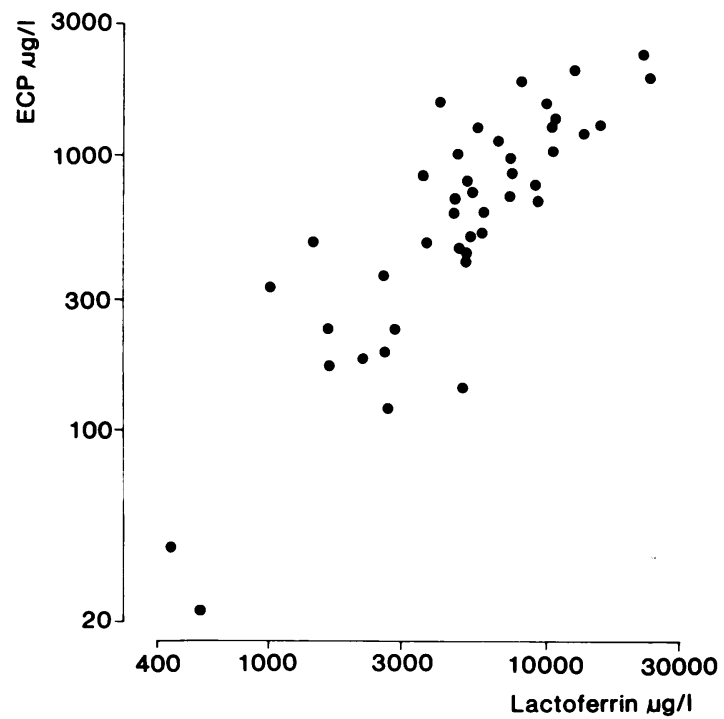

Fig. 3 Correlation of the concentration of ECP with lactoferrin in synovial effusions of patients with rheumatoid arthritis. The correlation is strong ( $n=44, r=0 \cdot 85$,

$p<0 \cdot 001)$. The equation of the regression line was log $E C P=1.048$ log lactoferrin -2.590 .

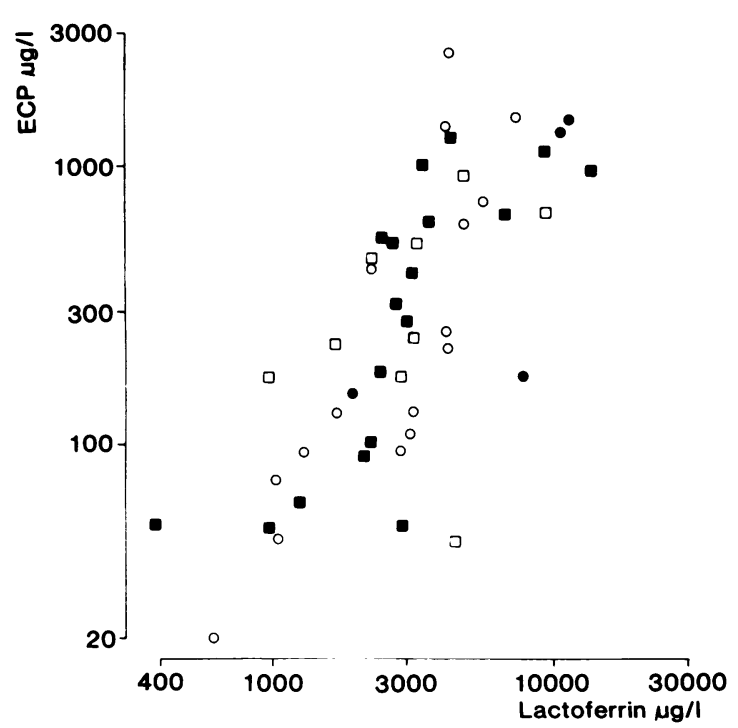

Fig. 4 Correlation of the concentration of ECP with lactoferrin in inflammatory synovial fluids from patients with reactive arthritis $(\bigcirc)$, Reiter's syndrome, psoriatic arthritis and sacroiliitis (ם), crystal arthritis (O), and unclassified arthritis ( $\square$ ). The correlation with reactive arthritis was significant $(n=16, r=0 \cdot 84, p<0 \cdot 001)$, as was the correlation with the other conditions taken together $(n=31, r=0 \cdot 68, p<0 \cdot 001)$. 

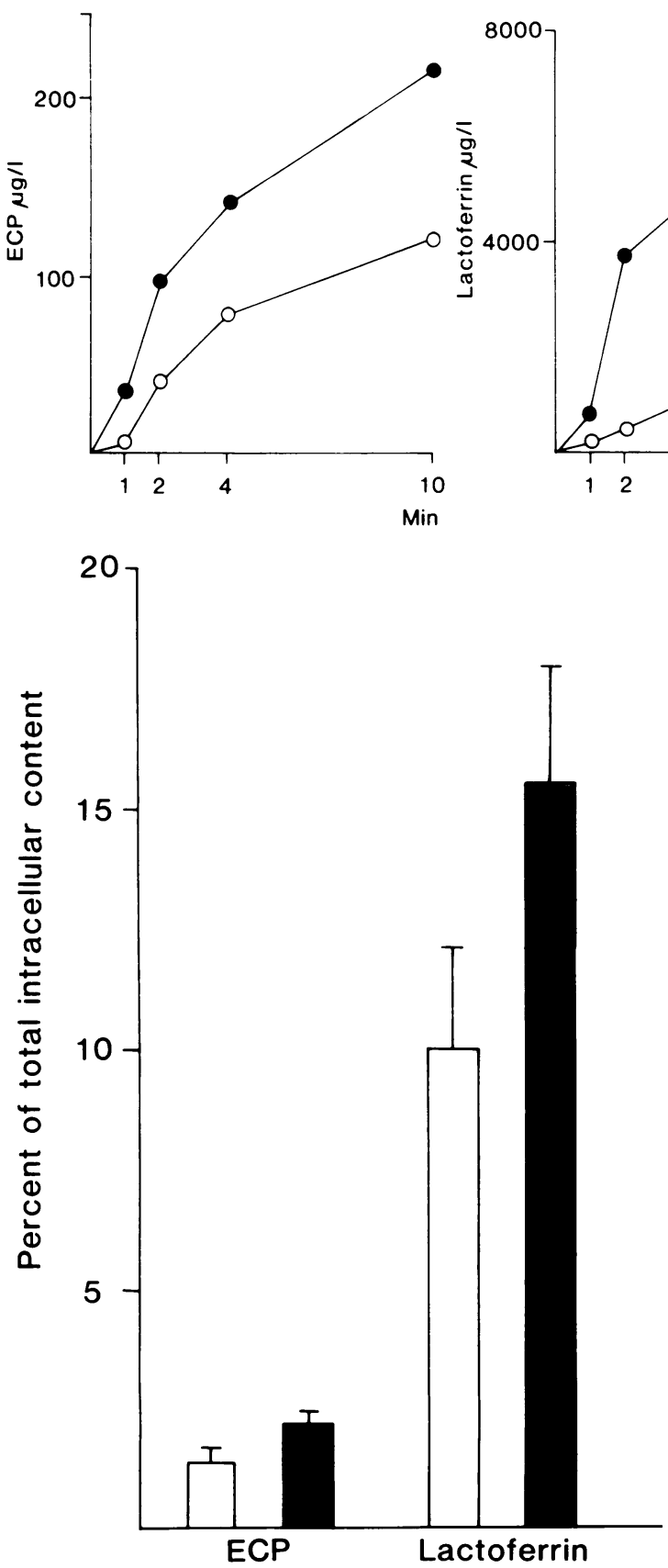

Fig. 6 The extracellular release of ECP and lactoferrin during a 10 min incubation of isolated granulocytes with agg $\operatorname{Ig} G$ only (open bars) or with agg $\lg G$ preincubated with NHS (solid bars). The final agg IgG concentration was $0.5 \mathrm{~g} / \mathrm{l}$. The amounts of ECP and lactoferrin released are expressed as percentage of the total intracellular content of the respective protein. Each bar represents means $\pm S D$ of six experiments.
Fig. 5 The time-dependent extracellular release of ECP and lactoferrin from isolated granulocytes when exposed to agg $\lg G$ only (open circles) or agg $\operatorname{Ig} G$ preincubated with NHS (closed circles). The final agg $\operatorname{Ig} G$ concentration was $0.5 \mathrm{~g} / \mathrm{l}$.
ECP and lactoferrin when experiments were performed with agg $\mathrm{IgG}$ at final concentrations ranging between 0.12 and $1 \mathrm{~g} / \mathrm{l}$. However, the release of lactoferrin was much more pronounced than the release of ECP in relation to the total intracellular content of these proteins. This was valid irrespective of whether agg IgG was preincubated with NHS or not (Fig. 6). The leakage of LD in the above experimental studies was similar in degranulation and control experiments.

\section{Discussion}

According to earlier observations ${ }^{3}$ and our own experience eosinophils are extremely rare in pathological synovial fluids, while neutrophils readily enter inflammatory synovial effusions. This apparent difference is surprising, since immunological mechanisms involved in many kinds of arthritis should not exclude the activation of eosinophils The present study may provide some understanding of the role of eosnophils in inflammatory joint reactions. The observation that inflammatory synovial effusions in the absence of eosinophils contain very high concentrations of ECP, a specific granule component of eosinophils, indicates a local release of eosinophil products probably due to degranulation of eosinophils in inflamed joints. Thus eosinophils seem to be involved to a significant extent in inflammatory joint reactions, and it is reasonable to assume that ECP originates from eosinophils reported to infiltrate the synovial tissue in arthritis. ${ }^{10}$ The factors responsible for local joint eosinophil accumulation and degranulation are unknown. However, these evidently operate in rheumatoid arthritis and psoriatic and reactive arthritides as well as in crystal arthritis but not in non-inflammatory arthritides. Moreover the degree of eosinophil 
activation as reflected by the synovial fluid concentrations of ECP seems to be closely related to the degree of neutrophil activation as assessed by the synovial fluid concentrations of lactoferrin, a specific granule constituent of neutrophils.

The uneven peripheral distribution of eosinophils in the inflamed joint cavity, ${ }^{310}$ the non-specifically raised ECP levels in inflammatory synovial fluids, and the evidence of parallel local activation of eosinophils and neutrophils in different arthritic conditions are all findings which are in accordance with the general behaviour of eosinophils observed in experimental local inflammatory reactions. Thus it is an old observation that eosinophils collect at the periphery of an inflammatory focus ${ }^{11-14}$ in contrast to neutrophils, which appear in the centre of the reaction. It is also known that eosinophils enter an area of inflammation by diapedesis in a manner similar to that of neutrophils ${ }^{15}$ and that in most inflammatory reactions several, non-selective chemotactic factors seem to be operative, attracting both neutrophils and eosinophils. ${ }^{16}$

The mechanisms by which eosinophil and neutrophil granular proteins are released from the cells into the synovial fluid are unknown. However, the dominating theory is that neutrophil granular constituents are released during phagocytosis of, for example, immune complexes in rheumatoid arthritis and urate crystals in gout. As with neutrophils, eosinophil phagocytosis is followed by coalescence of lysosomal granules with the phagocytic vacuole and release of granular proteins, not only into the phagosome but also externally. ${ }^{17}$ In order to test the hypothesis that immune complexes in synovial fluid may be one factor inducing neutrophil as well as eosinophil degranulation, we incubated isolated peripheral granulocytes with aggregated IgG in different concentrations and for varying times. Although IgG complexes generally induced a similar degranulation pattern for both neutrophils and eosinophils, it was evident that the extent of degranulation was considerably less for eosinophils. Phagocytosis by eosinophils has previously been reported to be less efficient than that of neutrophils. ${ }^{18-20)}$ Taken together these observations cast doubt on phagocytosis as the major mechanism behind local eosinophil degranulation in arthritis, but raise the possibility of alternative mechanisms such as secretion of granular constituents from eosinophils during their chemotactic movement into the joint cavity. The relationship between the concentrations of neutrophil and eosinophil constituents in inflammatory synovial fluid might also suggest that products released from phagocytosing neutrophils govern eosinophil accumulation and secretion in the inflamed joint. And in fact a substance very similar to ECF-A (eosinophil chemotactic factor of anaphylaxis), which induces a selective attraction of eosinophils, has been reported to be released from activated neutrophils. ${ }^{21}$

The role of eosinophils in inflammation remains an enigma. The earlier hypothesis that eosinophils have an anti-inflammatory role ${ }^{11}$ has gained some support by the recent observations on inhibition of mastcell or basophil mediated reactions by eosinophils. ${ }^{22}{ }^{23}$ However, even if eosinophils have a modulatory and controlling role in inflammatory reactions, one cannot exclude additional harmful tissue effects of eosinophil products. Thus the effect of ECP on coagulation, ${ }^{24}$ may result in thrombi in the joint microcirculation, and the cytotoxicity of this protein ${ }^{25} 26$ and major basic protein ${ }^{27}$-another eosinophil granular component-could possibly damage the joint tissue. The hypothesis that eosinophils themselves, and particularly their cytotoxic products, might be involved in the development of organ lesions has gained clinical and experimental support by recent studies on eosinophilic endomyocardial disease ${ }^{28}$ and bronchial asthma. ${ }^{29}$

This work was supported by grants from the Swedish Medical Research Council

\section{References}

1 Olsson I, Venge P, Spitznagel I K. Arginine-rich cationic proteins of human eosinophil granules. Comparision of the constituents of cosinophilic and neutrophilic leukocytes. Lab Invest 1977: 36: 493-500.

2 Venge P. Roxin L-E, Olsson I. Radio-immunoassay of human cosinophil cationic protein. Br J Haematol 1977; 37: 331-5.

3 Ropes M W, Bauer W. Synovial fluid changes in joint disease. Cambridge: Harvard University Press, 1953: 38-45.

4 Weissmann G. Activation of neutrophils and the lesions of rheumatoid arthritis. J Lab Clin Med 1982; 100: 322-33.

5 Spitznagel J K. Dalldorf F G. Leffell M S, et al. Character of azurophil and specific granules purificd from human polymorphonuclear lcukocytes. Lab Invest 1974; 30: 774-85.

6 Olofsson T, Olsson I, Venge P. Elgefors B. Scrum mycloperoxidase and lactoferrin in neutropenia. Scand $J$ Haematol 1977; 18: 73-80.

7 Hällgren R. Stălenheim G. Quantification of phagocytosis by human neutrophils. The use of radiolabelled staphylococcal protein A-IgG complexes. Immunology 1976: 30: 755-62.

8 Wroblewski F. LaDue J S. Lactic dehydrogenase activity in blood. Proc Soc Exp Biol Med 1955: 90: 210-3.

9 Ludlam C A. Moore S. Bolton A E, Pepper D S, Cash J D. The relcase of a human platelet-specific protein measured by radioimmunoassay. Thromb Res 1975; 6: 543-8.

10 Panush R S. Franco A E, Schur P H. Rheumatoid arthritis associated with eosinophilia. Ann Intern Med 1971: 75: 199205.

11 Schwartz E. Die Lehre von der allgemeinen und örtlichen Eosinophilic. Ergeh Allg Pathol Anat 1914: 17: 137-87.

12 Glaser R J. Wood Jr, W B. Pathogenesis of streptococcal pneumonia in the rat. Arch Pathol 1951: 52: 244-52.

13 Stecle $R \mathrm{H}$. Wilhelm $\mathrm{D} \mathrm{L}$. The inflammatory reaction in chemical injury III. Leukocytosis and other histological changes induced by superficial injury. BrJ Exp Pathol 1970); 51: 265-79. 
14 Bass D A. Bchaviour of cosinophil leukocytes in acute inflammation. II. Eosinophil dynamics during acutc inflammation. J Clin Invest 1975; 56: 870-9.

15 Marchesi V T. Florey H W. Election micrographic observations on the emigration of leukocytes. $Q J$ Exp Physiol 196): 45: 343-8.

16 Becson P B, Bass D A. The eosinophil. Philadelphia: Saunders. 1977: $58-70$

17 Butterworth A E. Sturrock R F. Houba V. Rees P H. Antibody dependent cell mediated damage to schistosomula in vitro. Nature 1975: 252: 5()3-5.

18 Cline M J. Hanifin J. Lehrer R I. Phagocytosis by human cosinophils. Blood 1968: 32: 922-34.

19 Mickenberg I D. Root R K. Wolff S M. Bactericidal and metabolic propertics of human cosinophils. Blood 1972; 39: 67-80.

20) Ishikawa T, Wicher K. Arbesman C E. In vitro and in vivo studics on uptake of antigen-antibody complexes by cosinophils. Int Arch Allergy Appl Immunol 1974; 46: 230-48.

21 Konig W, Czarnetzki B M, Lichtenstein L M. Eosinphil chemotactic factor (ECF) II. Relcase from human polymorphonuclear leukocytes during phagocytosis. J Immunol 1976; 117 : 235-41.

22 Hubscher T. Rolc of the cosinophil in the allergic reactions II Release of prostaglandin from human cosinophilic leukocytes. $J$ Immunol 1975; 114: 1389-93.
23 Zeiger R S. Twarog F J. Colten H R. Histaminasc releasc from human granulocytes. I Exp Med 1976: 144: 1049-61.

24 Venge $P$. Dahl R. Hällgren R. Enhancement of $F \times 11-$ dependent reactions by eosinophil cationic protein. Thromh Res 1979; 14: 641-9.

25 Venge $P$. Dahl R. Fredens K. Hällgren R. Pettersson C. Eosinophil cationic proteins (ECP and EPX) in health and discasc. In: Yoshida T. Torisu M. eds. Immunobiology of the eosinophil. New York. Oxford. Amsterdam: Elsevier Biomedical, 1982: 163-79.

26 McLaren D J. McKean J R, Olsson I, Venge P. Kay A B Morphologic studies on the killing of schistosomula of Schistosoma mansoni by human eosinophil and neutrophil cationic protcin in vitro. Parasite Immunol 1981; 3: 359-73.

27 Ackerman S J. Durack D T. Gleich G J. Eosinophil effector mechanisms in health and discase. In: Gallin J I, Fauci A S, cds. Advances in host defense mechanisms. New York: Raven Press. 1982; 1: 269-293.

28 Spry C J F, Davies J. Tai P-C. Fattah D. The pathogenesis of cosinophilic endomyocardial discase. In: Yoshida T, Torisu M. eds. Immunobiology of the eosinophil. New York. Oxford. Amsterdam: Elsevicr, 1983: 229-44.

29 Frigas E, Loegering D A, Solley G O, Farrow G M. Gleich G J Elcvated levels of the cosinophil granule major basic protein in the sputum of patients with bronchial asthma. Mavo Clin Proc 1981; 56: 345-53. 